\title{
A REPRODUTIBILIDADE TÉCNICA E O UNIMÚSICA: uma leitura interdisciplinar
}

Rubens Clair VIANA FILHO ${ }^{1}$

Maria de Lourdes BORGES ${ }^{2}$

\begin{abstract}
${ }^{1}$ Mestrando em Memória Social e Bens Culturais no Centro Universitário La Salle/Canoas.
\end{abstract} E-mail: rubens.unilasalle@ outlook.com

${ }^{2}$ Doutora em Administração. Psicóloga. Pesquisadora e professora do PPG Memória Social e Bens Culturais no Centro Universitário La Salle/Canoas. E-mail: maluborg@gmail.com

Recebido em: 12/03/2016 - Aprovado em: 15/07/2016 - Disponibilizado em: 18/12/2016

\begin{abstract}
RESUMO
O objetivo deste artigo é o de propor uma análise do Projeto Unimúsica sob responsabilidade da Pró-Reitoria de Extensão da Universidade Federal do Rio Grande do Sul através do conceito de reprodutibilidade técnica de Walter Benjamin. Sob um ponto de vista interdisciplinar e da gestão cultural, considera-se que o entendimento de Benjamin (1955) pode ser um importante elemento para a ajuda na compreensão das ações musicais do ponto de vista da reprodutibilidade técnica que acontecem no Projeto Unimúsica desde o ano de 1981. A metodologia é exploratória utilizando-se a análise do conteúdo de dados secundários sobre o projeto, tais como entrevistas e relatórios. Os resultados indicam que há uma certa manutenção sobre o culto a obra de arte musical, sendo em apresentações presenciais ou mesmo quando se apresenta ao espectador por outros meios tecnológicos, permitindo o seu reconhecimento e a sua identificação. Assim sendo, abre-se a possibilidade para além da obra de arte circunscrita aos espaços restritos ao seu local de origem, para a apreciação e divulgação para todos, tal como coloca Benjamin (1955) sobre a reprodutibilidade técnica.
\end{abstract}

Palavras-chave: Unimúsica, UFRGS, reprodutibilidade técnica, gestão cultural

\section{TECHNOLOGICAL REPRODUCIBILITY AND UNIMÚSICA: an interdisciplinary reading}

\begin{abstract}
This main is to propose an analysis of Unimúsica Project of UFRGS through the concept of technological reproducibility of walter Benjamin. Under an interdisciplinary y reading and cultural management, the contribution of the Benjamin (1955) may be an important element in helping to under standing the musical actions that happened in Unimúsica since 1981. The methodology is exploratory using the content analysis of secondary data on the project. The results shows that there is some main tenance on the cult of musical work of art, attendance to spectator by other technological means of presentations, allowing their recognition and identification. Therefore, it opens the possibility beyond the work of art confined to areas restricted o their place of origin, for the appreciation and dissemination to all, as Benjamin puts (1955) on technical reproducibility.
\end{abstract}

Keywords: Unimúsica, UFRGS, technological reproducibility, cultural management.

\section{Introdução}

Este artigo apresenta um olhar interdisciplinar sobre o Unimúsica ${ }^{1}$, um dos principais projetos de extensão da Universidade Federal do Rio Grande do Sul

${ }^{1}$ http://www.ufrgs.br/difusaocultural/programacao.php? $\underline{\mathrm{id}=3 \& \text { ano }=2015}$
(UFRGS) desde 1981. O Unimúsica é um projeto aplicado em uma Instituição de Ensino Federal, que se propõe a cumprir com o objetivo dar vazão às manifestações artísticas musicais daqueles que participam da Instituição e de fora dela. Com mais de trinta anos de existência, o Unimúsica se consolidou perante a comunidade externa e interna à 
Universidade. O presente artigo propõe uma análise do Projeto Unimúsica da UFRGS pela lente do entendimento de reprodutibilidade técnica de Walter Benjamin.

Considera-se que o entendimento de Benjamin (1955) pode ser um importante elemento para a ajuda na compreensão das ações musicais do ponto de vista da reprodutibilidade técnica que acontecem no Unimúsica. Diante do texto 'A Obra de Arte na Era da Sua Reprodutibilidade Técnica' do autor, é possível compreender a evolução das reproduções técnicas de representação das obras de arte, permitindo uma compreensão sob o aspecto da complementariedade.

Para Benjamin (1955) existem certas características nas obras de arte que não podem ser observadas a olho nu. Por exemplo, uma pessoa que observa uma obra arquitetônica como a torre Eiffel, sob os ângulos possíveis ao alcance do olho humano ou mesmo pela impossibilidade da proximidade física, certos aspectos ou detalhes do monumento acabam imperceptíveis ao observador. Porém quando reproduzidos pela imagem fotográfica ou cinematográfica, a imagem permite a observação com a precisão das lentes, obtendo maior riqueza das formas e ângulos que normalmente seriam impossíveis de serem vistos. Nesse sentido, a difusão das obras musicais podem ser também analisadas inicialmente devido ao advento da impressão gráfica, permitiu a reprodução das partituras, difundindo de maneira elementar as composições musicais. Posteriormente a gravação sonora, transpondo a barreira do local de execução da música, permitiu a audição da obra musical. Hoje com os recursos digitais, há a instantaneidade da reprodução de áudio e vídeo com maior qualidade.

A compreensão sob o aspecto da complementaridade acaba gerando novas possibilidades aos autores das obras musicais, e permitindo ao espectador o seu reconhecimento através de outros meios. A multiplicidade dos meios de reprodutibilidade, responde a uma nova necessidade tecnológica, atendendo a uma demanda de visão social. Estabelece novas relações de exibição e, incorpora nova forma ao culto das obras de arte, alterando o conceito nas relações de consumo da arte. Além disso, tal multiplicidade cria um outro espectro de valores, agrega um novo foco ao culto, como produto de massas possibilitando ao espectador uma visão a partir de diversos meios, sem fragmentar seu culto, mas agregando novas perspectivas ao espectador. Permite ainda um caleidoscópio de observações que se agregam pela complementaridade da técnica com a arte e sua reprodução (BENJAMIN, 1955).

Se a reprodução técnica da obra de arte liberta o objeto reproduzido do aqui e agora, ao multiplicá-lo, altera seu local de ocorrência único para uma ocorrência em 
massa (BENJAMIN, 1955); então o Unimúsica, por se tratar de um espaço de audição musical que ocorre nos meios acadêmicos, mostra através dos registros de imagem e de som a possibilidade da difusão para além do seu próprio meio e para a sociedade. $\mathrm{O}$ registro permite também o estudo acadêmico da composição ou execução do autor, criando possibilidade de visitar e revisitar, por tantos quantos queiram conhecêla.

Este artigo utiliza uma metodologia exploratória utilizando-se dados secundários sobre o Unimúsica, tais como entrevistas em revistas e relatórios analisados sob o a lente do referencial teórico construído a partir de Benjamin (1955) e sobre alguns de seus comentadores brasileiros. A estrutura do artigo apresenta o referencial teórico seguido de uma seção sobre espaços de música em universidades brasileiras. $\mathrm{O}$ artigo é finalizado com uma discussão sobre o projeto Unimúsica e com as considerações finais.

\section{Referencial Teórico}

Considera Benjamim (1955), que as obras de arte sempre podem ser imitadas e, portanto, reprodutíveis. No entanto, aponta que a reprodutibilidade técnica era considerada na época algo novo, que vinha relativamente se estabelecendo de forma descontinuada e crescente ao longo da história. A trajetória da reprodutibilidade inicia na Grécia antiga. O autor observa que os primeiros objetos que foram reproduzidos que se tem conhecimento foram as moedas. Por meio da experiência com a reprodução de moedas, apenas a fundição e a cunhagem eram conhecidas pelos gregos, como processo de reprodução. Naquele momento histórico, as demais obras de arte eram consideradas como únicas, pois não podiam ser reproduzidas tecnicamente.

Posteriormente, a xilogravura permitiu a reprodutibilidade das obras gráficas e subsequentemente a impressão, viabilizando a reprodução da escrita. No início do século XIX surge a litografia proporcionado às artes gráficas a otimização no processo de impressão, permitindo maior dinâmica na alternância da reprodução das imagens do cotidiano. Algumas décadas após esse período, foi criada a fotografia acelerando o processo de reprodução de imagens e, conjuntamente com a escrita a ilustração dos textos. Por conseguinte, surge o filme e, posteriormente a possibilidade da gravação sonora.

A reprodutibilidade técnica se intensificou trazendo consigo um conjunto de reflexões, conforme descreve Benjamin:

"No início do século XX, a reprodução técnica tinha atingido um nível tal que começara a tornar objeto seu, não só a totalidade das obras de arte provenientes de épocas anteriores, e a submeter os seus efeitos às modificações mais profundas, como também a conquistar o seu próprio lugar entre os procedimentos artísticos. " (BENJAMIN, 1955, p. 3).

$$
\text { Benjamin (1955) salientaque, na }
$$
reprodução técnica,não há a existência do 
"aqui e agora da obra de arte" como parte integrante da identidade que a constitui, conferindo mesmo assim a sua autenticidade. Isto proporciona à obra de arte sua autoridade. Salineta0se que a reprodução técnica propõe certa autonomia, como no exemplo da fotografia, que pode retratar detalhes de uma obra imperceptíveis ao espectador, através de um 'zoom' ótico ou determinados ângulos, exibindo nuances que não poderiam ser observados sem esses recursos.

Em outro aspecto, Benjamin (1955) apresenta a questão da portabilidade, a qual permite ao expectador observar a obra fora do seu contexto original, como por exemplo,quando uma obra sinfônica é executada em um determinado local e, através da gravação sonora, proporciona ao ouvinte sua reprodução em outro local, distante daqueleno qual se originou. Dessa maneira, torna-sepossível a exibição ou execução das obras em locais ou situações onde os originais não conseguiriam atingir.

Portanto, a reprodução técnica da obra de arte liberta o objeto reproduzido do aqui e agora e ao multiplicá-lo, altera seu local de ocorrência único para ocorrência em massa, além da qual não seria possível a disseminação do objeto de arte e promove sua renovação, revivendo obras produzidas por grandes autores (como por exemplo Heitor Villa-Lobos, Johann Sebastian Bach, Richard Wagner, Ludwig Van Beethoven). Embora Benjamin (1955) considere o empobrecimento da aura da obra de arte, pela representatividade da sua reprodutibilidade técnica, uma vez que esta não retrata a singularidade da criação (ou seja, a percepção do contexto que o artista manifestou para criar sua obra), considera também que, ao mesmo tempo é o que a reverencia. Isso porque essaimportância mostra-se através da reprodução, mantendo seu vigor, transpondo esta relação e multiplicando seu valor social.

Uma importante reflexão que Benjamin (1955) salienta é sobre a emancipação da obra de arte através da sua reprodutibilidade técnica, retirando da obra de arte da sua condição estática, física, do local de origem da sua existência, para uma condição de reprodução de obra de arte, sem portanto, demovê-la de sua categoria de arte. A condição de multiplicidade da reprodutibilidade da obra, através de uma imagem fotográfica por exemplo, não retira a autenticidade das cópias. Porém, diante disso, o que poderia ser considerado éque a perda do padrão de autenticidade da obra fundamentase em outro paradigma, o da instância política, ou seja, a mudança estabelecida ao rito do culto para uma outra prática da ordem da função social da sua exposição.

Quanto à recepção da obra de arte verifica-se a existência de dois polos, distinguindo-os entre o valor ao culto e o valor à exposição da obra. Porém segundo Benjamin (1955) face à evolução e os diversos meios de reprodutibilidade técnica, 
potencializou-se muito o fator da exposição da obra de arte, promovendo uma alteração entre os polos no seu conceito original, que se traduziu como uma alteração qualitativa.

O valor ao culto traz consigo o fato de que as obras de arte mais antigas surgiram a serviço de rituais, sendo primeiramente mágicos e posteriormente religiosos. $\mathrm{O}$ autor ressalta a importância da manutenção na existência dessa aura de certa maneira mágica, sob o aspecto de que essa, nunca se desligue integralmente da sua atribuição ritualística.Nas palavras do próprio autor "o valor singular da obra de arte "autêntica" tem o seu fundamento no ritual em que adquiriu o seu valor de uso original e primeiro" (BENJAMIN, 1955, p. 6).

$\mathrm{O}$ aqui e agora da obra de arte profere a sua originalidade e o seu conceito de autêntica, não podendo se atribuir o mesmo conceito à reprodutibilidade técnica.A autenticidade da obra de arte é o conteúdo primordial do relato de sua existência, permitindo a narrativa de tudo que nela é transmissível, desde sua duração material, origem e testemunho histórico. A respeito do filme cinematográfico, suscita o autor, de que a arte exige o recolhimento por parte do observador, questionando se ela proporciona uma análise do cinema.

"A diversão e o recolhimento formam um contraste que nos permite a seguinte formulação: aquele que se recolhe perante a obra de arte, mergulha nela, entra nesta obra, como esse lendário pintor chinês ao contemplar sua obra acabada. Pelo contrário as massas em distração absorvem em si a obra de arte" (Benjamin, 1955, p. 18).
$\mathrm{Na}$ época em que Benjamin escreveu sua obra, a gama dos recursos tecnológicos existentes, não contemplavam o conjunto de possibilidades de reprodutibilidade técnica que hoje permitem as novas formas de reprodutibilidade e de arte. Com a inovação tecnológica através dos recursos digitais e o ciberespaço, ampliou-se consideravelmente a série de possibilidades, permitindo novas formas de arte, inclusive aquelas geradas a partir da própria reprodutibilidade, tais como imagens de vídeo, projeções holográficas e bricolagem sonoras, criando um amplo espectro de possibilidades, antes inexistente.

Todavia essas inovações, não retiram a atualidade dos conceitos tecidos por Benjamin (1955), pois suas ideias apresentam fundamentos plenamente vigentes no que tange à reprodutibilidade nos tempos de hoje. Isso porque a aura como momento único da criação do artista, está presente nas possibilidades em que a tecnologia pode intervir na criação dos trabalhos artísticos. O contexto atual em que a reprodutibilidade ocorre é apresentada na seguinte seção.

\subsection{O contexto da músicae sua} reprodutibilidade

A reprodutibilidade técnica, vista no contexto atual infere novos questionamentos com referência às novas tecnologias, que permeiam as relações da arte e do culto.

O princípio da comunicação de massa originalmente constituída“um-todos", deu 
espaço a uma nova matriz "todos-todos", resultante da universalização das redes de dados, na qual emissores e receptores, artistas e público, com referência a produção artística se misturam ou revezam papéis, o mesmo se sucedendo na música. (PEREIRA DE SÁ, 2003).O constante e democrático ingresso dos músicos a técnica da gravação se estabelece a partir da introdução do protocolo de hardware/software MIDI (Music Instrument Digital Interface) em 1983, viabilizando fusão de samplers, sintetizadores digitais, baterias eletrônicas com computadores ligados em rede, firmando a concepção de home studio (PEREIRA DE SÁ, 2003, p.10). Tais aparelhosoriginam a sustentação de uma nova estética sonora, que enriquece os detalhes sonoros, propiciando assim a diferenciação de ruídos, diversificação de timbres ou ritmos, pausas e outras sutilidades da exibição sonora que irão dar valor na apreciação musicalgerando uma noção de high fidelity. Isso cria a possibilidade da customização musical, por intermédio de recursos da equalização entre graves e agudos, samplers e controles do volume e assim por diante (PEREIRA DE SÁ, 2003, p.14).

Assim sendo, torna-se essencial a educação cognitiva para utilizar os dispositivos digitalizadores, uma vez que é necessário um entendimento científico tecnológico maior e mais aprofundado, com o uso dos novos equipamentos, para prover a capacidade de reprodutibilidade dos sons que estes recursos podem oferecer (PEREIRA DE SÁ, 2003, p.14).Outro aspecto diz respeito a desmaterialização da música, que a partirda digitalização em bits cria a possibilidade de serem acessados, lidos e transpostos a outros suportes alteráveis, permitindo por meio de softwares específicos ser misturada com outros sons, sampleada e modificada infinitamente (PEREIRA DE SÁ, 2003, p.15). Parte-se de um pressuposto que a cibercultura, que se identifica pela digitalização da arte, possa afastar ainda mais a aura da obra de arte (MARTINS, QUEIRÓS, 2012).

"No tocante à aura, a questão apresenta uma maior complexidade. Por isso, sugerimos apenas a hipótese que os shows de rememoração envolvem afetividades, experiências e sensações, e a digitalização pode proporcionar tanto o distanciamento quanto aproximação de um determinado momento do aqui e agora"(MARTINS, QUEIROZ, 2012, p.11).

Neste sentido para Pereira de Sá (2003, p.15) a comodificação da música denota a tensão entre o consumo no âmbito público e privado, uma vez que transfere uma parte da reprodutibilidade técnica para a esfera doméstica, com qualidade de som, anteriormente disponível para audição somente em salas de concertos. Além disso, a partir desses novos suportes, vem ocorrendo também a desintermediação da música, uma vez que abre a possibilidade de divulgação e distribuição em rede, sem a necessidade da intermediação dos empresários do ramo musical e das gravadoras (PEREIRA DE SÁ, 2003, p.16). 
Esses novos suportes oportunizam ao usuário participar ativamente do processo, gerando uma nova forma de entretenimento, com ênfase na noção de consumo participativo. (PEREIRA DE SÁ, 2003, p.16). Porém, Benjamim (1955) não considera a reprodutibilidade técnica uma novidade do sistema capitalista, uma vez que de acordo com o autor, sempre houve meios de reprodução da arte. Porém para Martins e Queirós (2012), Benjamin considera novidadea forma de reprodução técnica que acompanha o aprimoramento das tecnologias, pois dessa maneira a reprodução técnica ascende a um nível de qualidade que transforma a obra de arte.(MARTINS, QUEIRÓS, 2012 p. 4).

O projeto Unimúsica é um importante projeto que congrega há décadas iniciativas e apresentações musicais na Universidade Federal do Rio Grande do Sul, o qual será apresentado e debatido a seguir.

\section{O Projeto Unimúsica da UFRGS e}

\section{Benjamin}

Com mais 30 anos de existência, o projeto Unimúsica é um exemplo de projeto aplicado em uma Instituição de Ensino Federal, que se propõe a cumprir como o objetivo de dar vazão às manifestações artísticas musicais daqueles que participam da Instituição.No seu contexto não só oportunizou ao público variada gama de apresentações, mas também entrevistas abertas, debates, palestras, oficinas e seminários. Apresentando uma programação não segmentada por gênero musical, possibilita ao público um amplo espectro de apresentações, dentre elas de música regional, erudita, folclórica e popular, com autores de várias nacionalidades. (PETRUCCI, 2011).

Apesar de reconhecida credibilidade no ambiente cultural gaúcho, a trajetória do Unimúsica não dispõe de registros de grande visibilidade e acessibilidade. Pouco material foi encontrado a esse respeito.

A Coordenadora do Projeto Unimúsica Ligia Antonela Petrucci conforme publicado na Revista de Extensão n 03 (2011, p.25 2), tece importantes observações sobre a trajetória do Projeto desde 1981:

"O fato é que por uma série de razões, inclusive políticas, o "projeto" decolou logo depois das primeiras edições, já não podendo ficar restrito as formações próprias do âmbito acadêmico, corais, orquestra juvenil e conjuntos de câmara. Muitos jovens músicos, não necessariamente vinculados à universidade, queriam mostrar o que estavam criando e muitos outros jovens, sobretudo estudantes, queriam ouvir o que eles tinham a propor. O resultado não foi pequeno: muitos dos jovens músicos que estavam ali iniciando suas carreiras passaram a ser identificados como a "geração da música". E o Unimúsica, por sua vez, passou a ser um projeto reconhecido por toda a sociedade."

Os aspectos políticos levantados por Petrucci (2011) são esclarecidos por Aquistapace (2002, p. 11 conforme registrado por Boettcher, 2010, p. 8):

"nunca houve interferência da Pró-Reitoria de Extensão, nem do Gabinete do Reitor, em nenhum espetáculo. Na época, não era uma coisa comum, estávamos no final de um regime de ditadura. [...] as pessoas tinham a liberdade de mostrar seu trabalho no palco. [...] Era uma decisão que tinha certas implicações." 
O Unimúsica foi construído ao longo de mais de três décadas com a participação dos seus gestores e foi sendo legitimado pela comunidade, pela sua importância tendo se consolidado realizando apresentações mensais, conforme informações apontadas junto ao Departamento de Difusão Cultural da UFRGS.Além disso, pelo que se sabe, o Projeto Unimúsica parte de um pressuposto básico democrático, uma vez que tinha em seus objetivos, esboçados ainda em 1981, criarum espaço para todos os seus agentes expressarem seus trabalhos. Isso acontecia nos primórdios do Unimúsica, inclusive por conta de haver poucos espaços em que jovens e intelectuais pudessem se expressar em um país ainda com características da ditadura militar.

Tratavam-se de implicações políticas, mas também de aprendizagem pois era uma época de experimentação tanto para o público, os artistas e para os organizadores, sendo que Ludwig Buckup, então Pró-Reitor de Extensão Universitária da UFRGS, foi o idealizador se inspirando em projetos de universidades europeias. (BOETTCHER, 2010).

Ao fazer uma relação com o entendimento de Benjamin (1955) fica claro que no início do projeto Unimúsica pode-se identificar a existência de um "aqui e agora da obra de arte", uma vez que se tornava um espaço em que jovens músicos podiam mostrar suas criações e, como entende o citado autor, ajudar a formar a identidade daquilo que constituía a obra, no caso, a obra musical.

Nesse sentido, o Unimúsica representava e ainda representa um espaço de expressão musical, atraindo apresentações de artistas com representação local, regional e nacional. Por exemplo em 2015, o Unimúsica promoveu apresentações de músicos de expressão nacional como Arrigo Barnabé, Jards Macalé, Wander Wildner, Luiz Melodia, Carlos Careqa, Tom Zé entre outros.

Torna-se salutar estabelecer uma relação entre o Unimúsica e o entendimento de Benjamin (1955) sobre a reprodutibilidade técnica da obra de arte. Como característica precípua, o Projeto Unimúsica apresenta importância como instrumento legitimador de um espaço cultural de música popular, no âmbito de uma Universidade Pública. Nos últimos anos compreende em sua variada programação projetos artísticos de outras regiões do país, inclusive de países vizinhos. (PETRUCCI, 2011).

Assim sendo pode-se considerar que o Unimúsica possui um papel deinstrumento legitimadorda música popular. Nesse sentido, através da reprodutibilidade técnica da música enquanto obra de arte, o Unimúsica pode ampliar a abrangência e popularidade da música e da cultura nela inserida, pois multiplica a obra de arte/música, libertando o objeto reproduzido do seu espaço físico inicial, alternado assim seu local de 
ocorrência único, para ocorrência em massa. "Julio Conte, dramaturgo, diretor teatral e psicanalista, na década de 80, aluno do Departamento de Arte Dramática"fala em entrevista à Boettcher (2010, p. 9) sobre a diferença voltada para o aqui e agora da obra musical:

"tu começa a perceber nos pequenos gestos, pequenos detalhes de interpretação. Uma coisa é fazer exercício na aula colegas fazendo comentários. Outra coisa é você ter 800 pessoas vendo e rindo da tua interpretação."

Observa-se nesse depoimento de um artista certo caráter de singularidade de cada apresentação musical que ele fazia no Unimúsica. Questiona-se o quanto há da aura da obra de arte no que se refere às apresentações musicais, tais como as que acontecem dentro do Projeto Unimúsica?Por meio da reprodução musical, há uma possibilidade de que a obra de arte mantenha o seu vigor, transpondo a relação da limitação do seu espaço físico e do contexto em que o artista criou sua obra, multiplicando assim seu valor social. Diante disso, poder-se-ia pensar que esses músicos estão unidos em prol da busca de um "aqui e agora da obra de arte" e quiçá de uma aura criativa em prol de sua autoridade embasada na autenticidade, como entendido por Benjamin (1955).

Sob todos aspectos considera-se a reprodutibilidade como um fator imprescindível na criação de projetos musicais como o Unimúsica, tal como já ocorre, quando os shows musicais são disponibilizados via gravação digital pela rede de computadores. Aqui há dois aspectos que evocam análise: o primeiro é que via gravação digital existem recursos de portabilidade (quase que inesgotáveis), permitindo ao expectador observar a obra fora do seu contexto original como as apresentações dentro do projeto Unimúsica. Em segundo lugar há a oportunidade de libertar a música enquanto obra de arte e o músico enquanto executor; não ficando restrito à audiência local no momento da sua execução, mas podendo disseminar a música promover sua renovação. Nesse sentido, a própria expressão musical contém tacitamente o elemento da reprodução, naquilo para o qual Benjamin chama a atenção, ou seja, para "o modo de reprodução técnica que acompanha o aperfeiçoamento das tecnologias" (MARTINS; QUEIRÓS, 2012, p. 4). Na velocidade das mudanças tecnológicas do tempo atual e seus inúmeros recursos tecnológicos, a reprodutibilidade da obra de arte permite inclusive gerar novas obras de arte, através dos recursos e da possibilidade de sua instantânea difusão e disseminação. A reprodutibilidade técnica hoje atravessa culturas e fronteiras, inferindo nossos conhecimento e conceitos à arte.

\section{Considerações Finais}

Ao propor uma leitura do projeto Unimúsica através do conceito de reprodutibilidade técnica de Walter Benjamin, foi realizada uma reflexão sobre a 
manutenção do vigor que uma obra de arte musical pode manter, mesmo transpondo a relação da limitação do espaço físico e do contexto em que o artista a criou. Dessa maneira, o próprio valor social de uma obra de arte musical tem a possibilidade de ser multiplicado. Além disso, a reprodutibilidade dentro do projeto Unimúsica engloba shows que podem ser acompanhados via rede de computadores ao vivo ou depois que aconteceram. Diante disso, diferentes ambientes e tecnologias usadas na execução, referem-se à multiplicidade dos meios de reprodutibilidade que pode trazer um novo foco ao culto das artes, conforme Benjamin (1955).

Ao olhar para a música enquanto obra de arte, o Unimúsica pode estar servindo como um instrumento legitimador da música popular, incentivando o seu caráter cultural nas apresentações e multiplicando o objeto por meio de sua reprodução, libertando-o do seu espaço físico inicial. A reprodutibilidade técnica, como apontado neste trabalho,pode permitir a contemplação da obra de arte fora do local que está apresentada originalmente. Sob este aspecto, entende-se que é mantido o culto a obra de arte, que se apresenta ao espectador por outros meios, permitindo o seu reconhecimento e a sua identificação, mesmo em outro contexto. Assim sendo, abre-se a possibilidade para além da obra de arte circunscrita aos espaços restritos ao seu local de origem, para a apreciação e divulgação para todos, tal como colocaBenjamin (1955) sobre a reprodutibilidade técnica.

Não foi aspiração deste artigo ter esgotado o assunto $\mathrm{e}$ análise sobre o Unimúsica a partir do entendimento de Benjamin (1955), porém considera-se que o projeto serviu como um pano de fundo para o entendimento das suas ideias. Além disso, o escasso material a respeito da trajetória do Unimúsica, seja em termos operacionais e estratégicos dificultou um maior aprofundamento analítico. Porém, as ideias de Benjamin (1955) podem lançar luz para ampliar a compreensão entre os estreitos laços da obra de arte e as implicações dos seus valores políticos, sociais e tecnológicos, tais como para uma maior politização da sociedade.

\section{REFERÊNCIAS}

BENJAMIN, W. A Obra de Arte na Era da Reprodutibilidade, 1955. Disponível em: http://www.ufrgs.br/obec/assets/acervo/arquiv o/benjamin_reprodutibilidade_tecnica.pdf Acesso em: 15 jun. 2015.

BOETTCHER, C. E. A. Política: Gestão ou Desejo? Qual o lugar da Cultura. Monografia. Especialização em Gestão Cultural da Universidade de Girona, Cátedra da UNESCO-ITAÚ Cultural. Porto Alegre, 2010.

MARTINS, G.; QUEIRÓS, T. Será um retorno da aura? Como analisar o aqui, agora na criação, produção e consumo da música. In: IV Encontro de Pesquisadores em Comunicação e Música Popular. Anais...Universidade de São Paulo ECA/USP, 2012. Disponível em: 
http://musica.ufma.br/musicom/trab/2012_GT 5_03.pdf Acesso em: 09 dez. 2015.

PEREIRA DE SÁ, S. A música na era de suas tecnologias de reprodução. Revista da

Associação Nacional dos

Programas de Pós-Graduação em

Comunicação: E-Compos. 2006. Disponível

em:

http://www.compos.org.br/seer/index.php/ecompos/article/viewFile/92/92Acesso em: 09 dez. 2015.

PETRUCCI, L. A. Projeto Unimúsica, o ouvinte nômade e a ampliação de repertórios.

Revista da Extensão, 2011. Disponível em: http://issuu.com/extensaoufrgs/docs/rev_ext_ web? $=3950560 / 3010878$ Acesso em: 20 ago. 2015. 